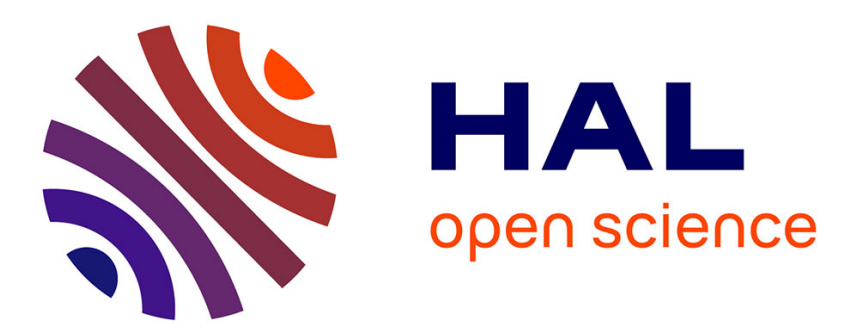

\title{
On the very long term delayed behavior of biaxially prestressed structures: the case of the containments of nuclear power plants
}

F. Benboudjema, J M Torrenti

\section{- To cite this version:}

F. Benboudjema, J M Torrenti. On the very long term delayed behavior of biaxially prestressed structures: the case of the containments of nuclear power plants. Concreep 2015, Sep 2015, Vienne, Austria. hal-01695981

\section{HAL Id: hal-01695981 \\ https://hal.science/hal-01695981}

Submitted on 29 Jan 2018

HAL is a multi-disciplinary open access archive for the deposit and dissemination of scientific research documents, whether they are published or not. The documents may come from teaching and research institutions in France or abroad, or from public or private research centers.
L'archive ouverte pluridisciplinaire HAL, est destinée au dépôt et à la diffusion de documents scientifiques de niveau recherche, publiés ou non, émanant des établissements d'enseignement et de recherche français ou étrangers, des laboratoires publics ou privés. 


\title{
On the very long term delayed behavior of biaxially prestressed structures: the case of the containments of nuclear power plants
}

\author{
F. Benboudjema ${ }^{1}$ and J. M. Torrenti ${ }^{2}$ \\ ${ }^{1}$ LMT-Cachan/ENS-Cachan/CNRS/Université Paris Saclay; email: \\ farid.benboudjema@ens-cachan.fr \\ ${ }^{2}$ Université Paris-Est, IFSTTAR, department Materials and Structures; email: jean- \\ michel.torrenti@ifsttar.fr
}

\begin{abstract}
The typical French reactor building consists of two concentric containments. The outer containment is made with reinforced concrete. The inner containment is biaxially prestressed, from 80 to $120 \mathrm{~cm}$ thick, and designed to withstand an internal pressure of $0.5 \mathrm{MPa}$ (absolute) in case of an accident. In order to avoid tensile stresses in concrete, a prestress is applied, corresponding to compressive stresses in concrete of about $8.5 \mathrm{MPa}$ and $12 \mathrm{MPa}$ along vertical and tangential directions, respectively. In order to maintain enough prestressing in the structure, the delayed behavior of concrete on the very long term should be correctly assessed.

The measurements of the very long term deformations of larges bridges and of nuclear containments seem to indicate that, on the very long term, creep strains are function of the logarithm of time. In particular, the measurements of delayed strains in the containment wall show two distinct kinetics:

- the difference between tangential and vertical strains, which exhibits a fast kinetics and becomes almost constant after 500 days,

- the average of tangential and vertical strains undergoes a slow kinetics. If vertical and tangential strains rates are equal (despite different values of the prestressing), this means that the long term biaxial creep deformations are only sensible to the mean stress and independent of deviatoric ones.

In the recent Model Code 2010 creep is expressed as a combination of an asymptotic and a logarithmic function. The logarithmic function corresponds to basic creep while drying creep is asymptotic. Using this model for delayed strains, and adding the possibility to adjust the parameters of the relations proposed by MC2010 on experimental results, the evolution of the strains is calculated and compared to in situ measurements. We finally discuss the set of adjusted possible parameters.
\end{abstract}

\section{INTRODUCTION - BASIC CREEP OF CONCRETE}

The typical French reactor building consists of two concentric containments (fig. 1). The outer containment, designed to sustain external aggressions, is made with reinforced concrete. The inner containment is biaxially prestressed, from 80 to 120 $\mathrm{cm}$ thick, and designed to withstand an internal pressure of $0.5 \mathrm{MPa}$ (absolute) in case of an accident. In order to avoid tensile stresses in concrete, a prestress is applied, 
corresponding to compressive stresses in concrete of about 8.5 MPa and 12 $\mathrm{MPa}$ along vertical $(\mathrm{zz})$ and tangential $(\theta \theta)$ directions, respectively. In the previous generation of French Nuclear Power Plant (NPP), there was no metallic liner inside the internal containment. So the tightness of the containment in case of an accident is only assured by concrete. To limit leakage, cracking should be avoided and, so, tensile stresses should remain below the tensile strength of concrete. That is why the evolution of prestressing forces during time is critical for the NPP operation and why a good prediction of the evolution of delayed strains of the containment is needed.

To predict the evolution of prestressing forces with time, the delayed behavior of the constitutive materials (relaxation for steel and creep and shrinkage for concrete) has to be modelled precisely on the long term. In this paper only creep of concrete is considered and two problems are discussed: is the very long term creep asymptotic or not and how to deal with biaxial stresses?

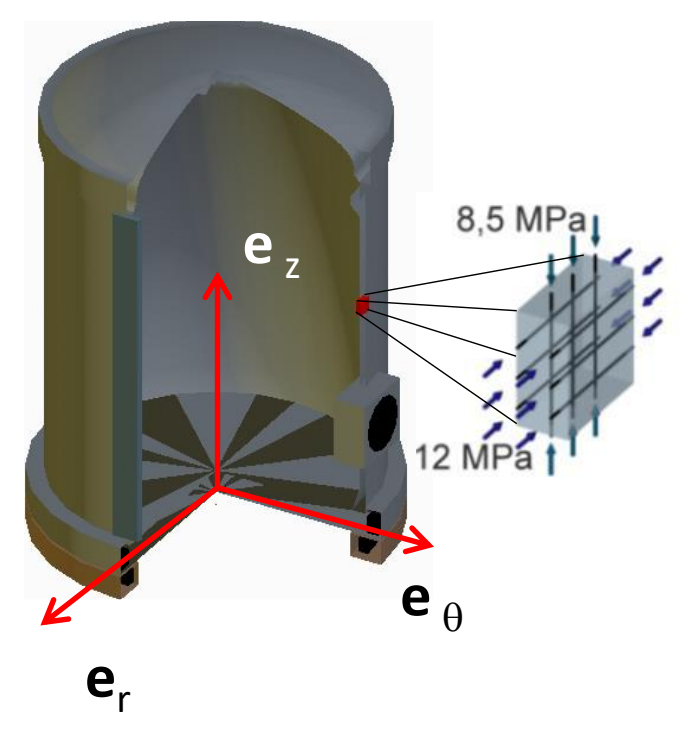

Figure 1. Simplified diagram of the containment and its prestressing.

\section{IS THE VERY LONG TERM CREEP ASYMPTOTIC?}

\section{Laboratory tests}

Classical creep tests in laboratory last generally less 2 or 3 years (and sometimes less). With such duration it is possible using these tests to fit as well an asymptotic or a logarithmic evolution of strains. There are nevertheless some basic creep tests performed by Brooks (Brooks, 2005) with a duration of 30 years, Troxell (Troxell, 1958) and Russell (Russel, 1989) with a duration of 20 years. These tests performed on concretes with different water to cement ratio and with different aggregates types, show that basic and total creep are not asymptotic (figure 2). It should be emphasized that, the specimens are either tested under water (Brooks, 2005) or tested under autogeneous conditions (Troxell, 1958; Russel, 1989). Thus, it means in the latter case, it is not sure that the specimens are not undergoing some parasite drying. 


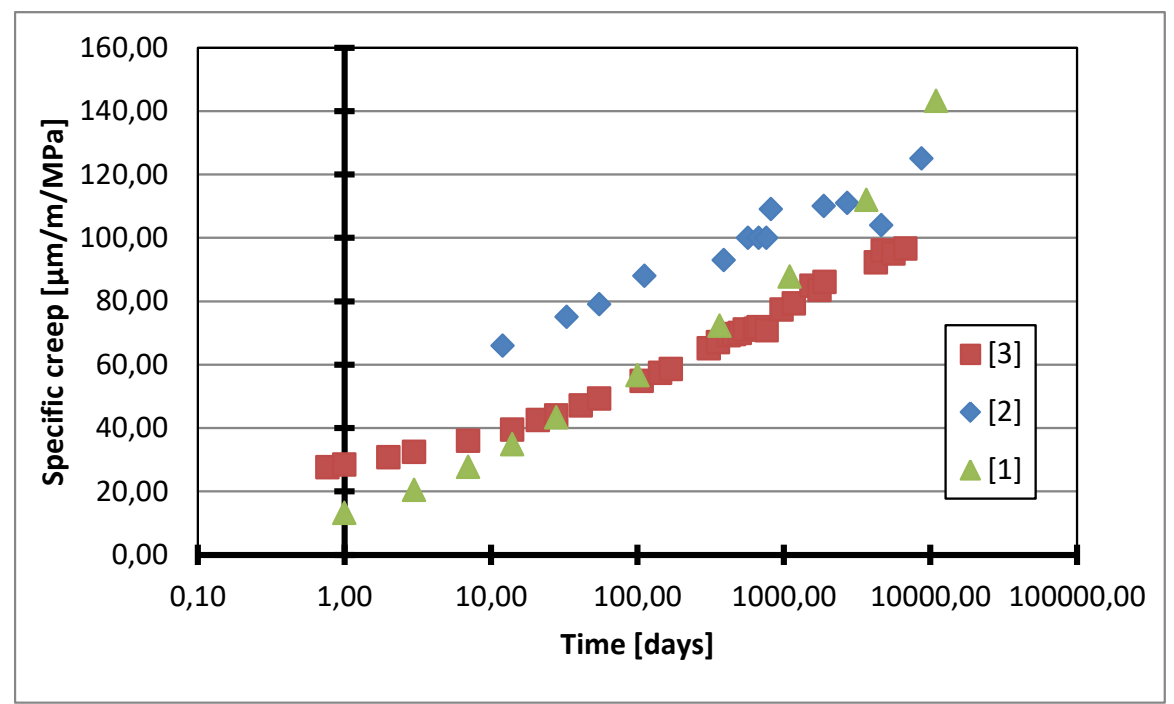

Figure 2. Basic creep of concrete; $[1]=($ Brooks, 2005), $[2]=($ Troxell, 1958) and $[3]=($ Russel, 1989)

\section{Long term deformations of prestressed structures}

The observation of the deflections of several bridges built by means of prestressed box girders indicates rather clearly that long term deflections are not asymptotic (Bazant et al., 2011) (Vitek and Křístek, 2000) (Sellin et al., 2015). In the case of NPP, thanks to a large monitoring of the behavior of the containment, global and local deformations are measured. Figure 3 presents the evolution of the deformations of the central part of the containment of three French NPP. The long term behavior in the two directions of the prestressing is not asymptotic and seems in accordance with a logarithmic evolution with time. Note that in the global behavior of the structure, the effects of drying shrinkage and relaxation of the prestressing tendons are included in the delayed strains.

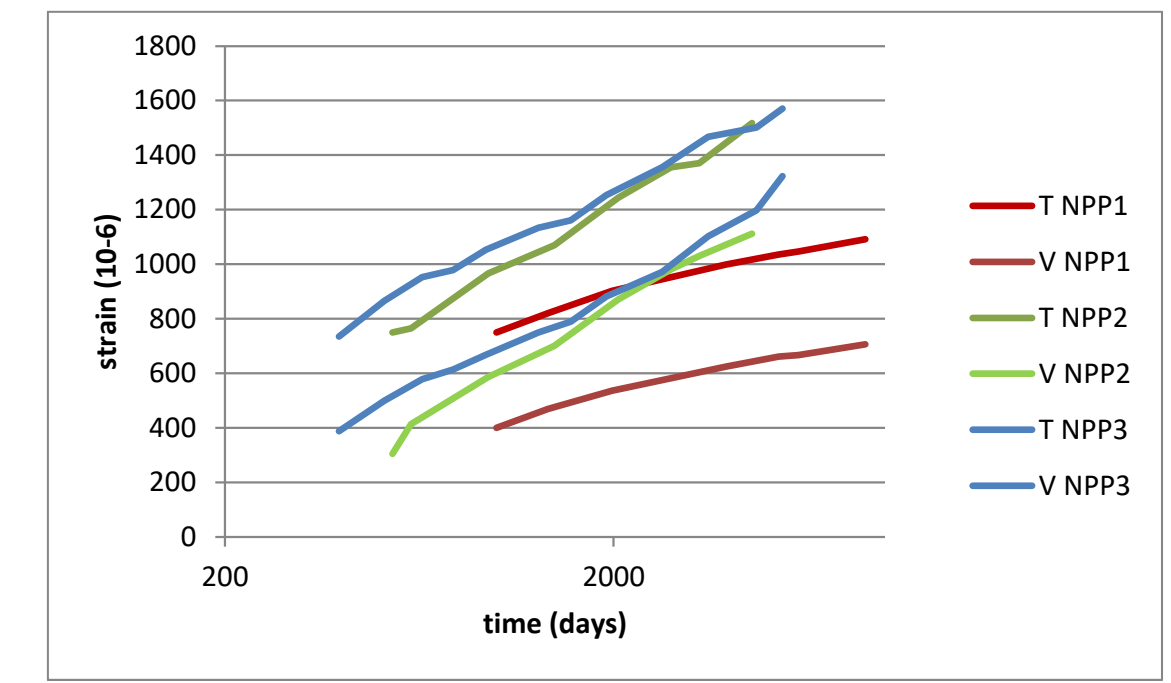

Figure 3. Evolution of the deformations in the central part of the containment of 3 NPP ( $V=$ vertical strains, $T=$ tangential strains $)$ 


\section{Consequences in codes}

In the actual Eurocode 2 (EN1992-1-1, 2005), creep is calculated by means of an asymptotic hyperbolic function (equation 1) while in the recent Model Code 2010 creep is expressed as a combination of an asymptotic and a logarithmic function (equation 2) (Muller et al., 2013). In the latter case the logarithmic function corresponds to basic creep while drying creep is asymptotic.

$$
\begin{aligned}
& \varepsilon=\frac{\sigma}{E c} a f_{1}(h)\left(\frac{t-t 0}{b g_{1}(h)+(t-t 0)}\right)^{c} \\
& \varepsilon=\frac{\sigma}{E c}\left[a f_{2}(h)\left(\frac{t-t 0}{b g_{2}+(t-t 0)}\right)^{c}+d \ln (1+e(t-t 0))\right]
\end{aligned}
$$

where $a, b, c, d$ and $e$ are fitted constants. $f_{1}, f_{2}, g_{1}$ and $g_{2}$ are functions of the notional size $h$ and the relative humidity $R H$. These functions are given by Eurocode 2 and MC2010.

Using these equations, it is possible to adjust the parameters on experimental results obtained in the laboratory by Granger (Granger, 1995). Figure 4 shows that it is possible to find a set of parameters that could fit the experimental results (at least on the long term which is the most important), for a sample with a diameter of $16 \mathrm{~cm}$ stored in a relative humidity $\mathrm{RH}=50 \%$, despite the fact that the used equations are very different.

The creep models being optimized on a sample, it is possible to predict the creep deformations of a larger structure. In our case, a structure with a notional size $\mathrm{h}=800 \mathrm{~mm}$ and loaded under a constant uniaxial stress of $12 \mathrm{MPa}$ and a $\mathrm{RH}$ of $50 \%$ is considered. Figure 5 shows that in this case at very long term large differences occur despite a good calibration of the model on the same test. This is of course due to the differences in the nature of the equations (asymptotic or not) and it shows the importance of the physical manner to model the very long term behaviour of concrete structures. It indicates also that the observation of the behaviour of a sample, even during 3 years, is not enough to predict the correct behaviour of a structure during several decades.

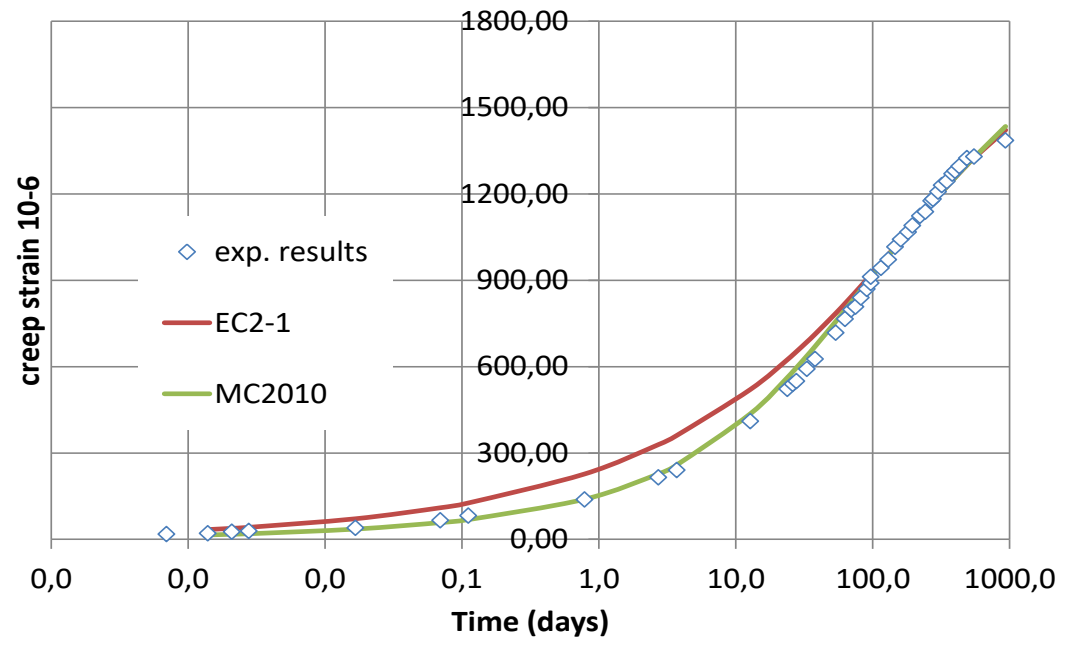

Figure 4. Comparison of experimental results $[8]$ and models corresponding to equations 1 and 2. $\sigma=12 \mathrm{MPa}, \mathrm{RH}=50 \%, \mathrm{~h}=80 \mathrm{~mm}$. 


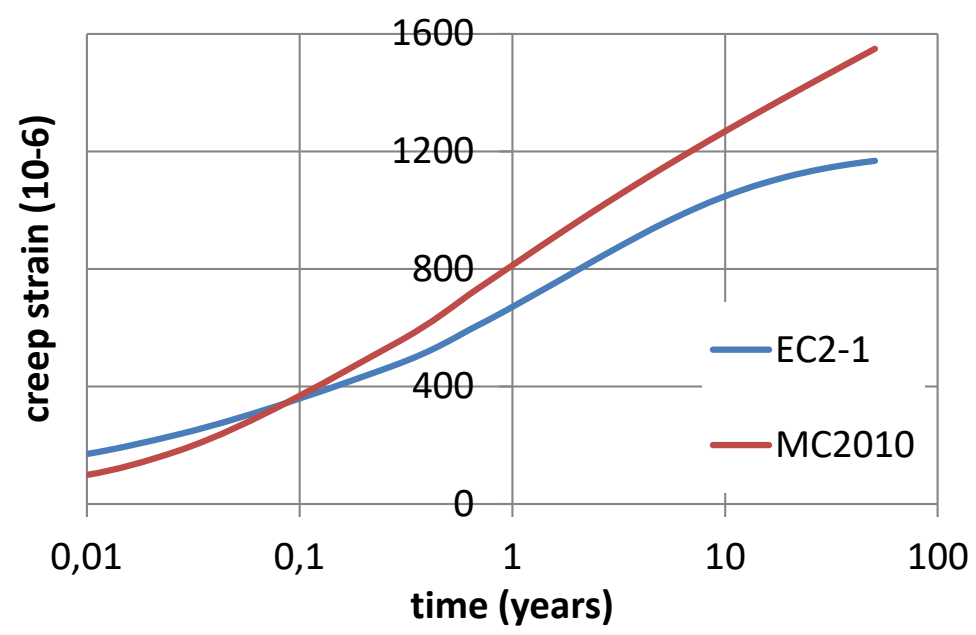

Figure 5. Comparison of the estimated creep strains using equations 1 and 2, parameters fitted on laboratory experiment, $\sigma=12 \mathrm{MPa}, \mathrm{RH}=50 \%, \mathrm{~h}=\mathbf{8 0 0 \mathrm { mm }}$

\section{LONG TERM DEFORMATIONS OF A NPP}

\section{Analysis of the behavior of containment vessels}

In Figure 3, the evolution of the biaxial deformations during times in a NPP was presented. From these deformations one can express the evolutions of the average and the difference of the vertical and tangential strains. These evolutions are presented figures 6 for the same three NPPs (Barré et al., 2014). It can be seen that the delayed strains in the containment wall follow two distinct kinetics:

- the difference between tangential and vertical strains, which exhibits a fast kinetics and becomes almost constant after 500 days,

- the average of tangential and vertical strains, which corresponds to a slow kinetics. If vertical and tangential strain rates are equal despite different values for the prestressing, this means that in the long term biaxial creep deformations are only sensible to the mean stress and independent of deviatoric ones. If biaxial creep is expressed using a tangent Poisson ratio, this is equivalent to a Poisson ratio equal to 1. This is what is proposed actually in Eurocode 2 part 1 (French national annex) for drying creep (NF EN 1992-2, 2005), as for basic creep it is proposed to use a Poisson ratio equal to the elastic one. It could be explained for instance if one assumes that drying creep is only an amplification of drying creep due to the loading (as proposed in (Sellier and Buffo-Lacarrière, 2009). In fact, the behavior of the containment vessel is also affected by other phenomena like drying shrinkage and relaxation of the prestressing. So a more complete modelling is needed. 


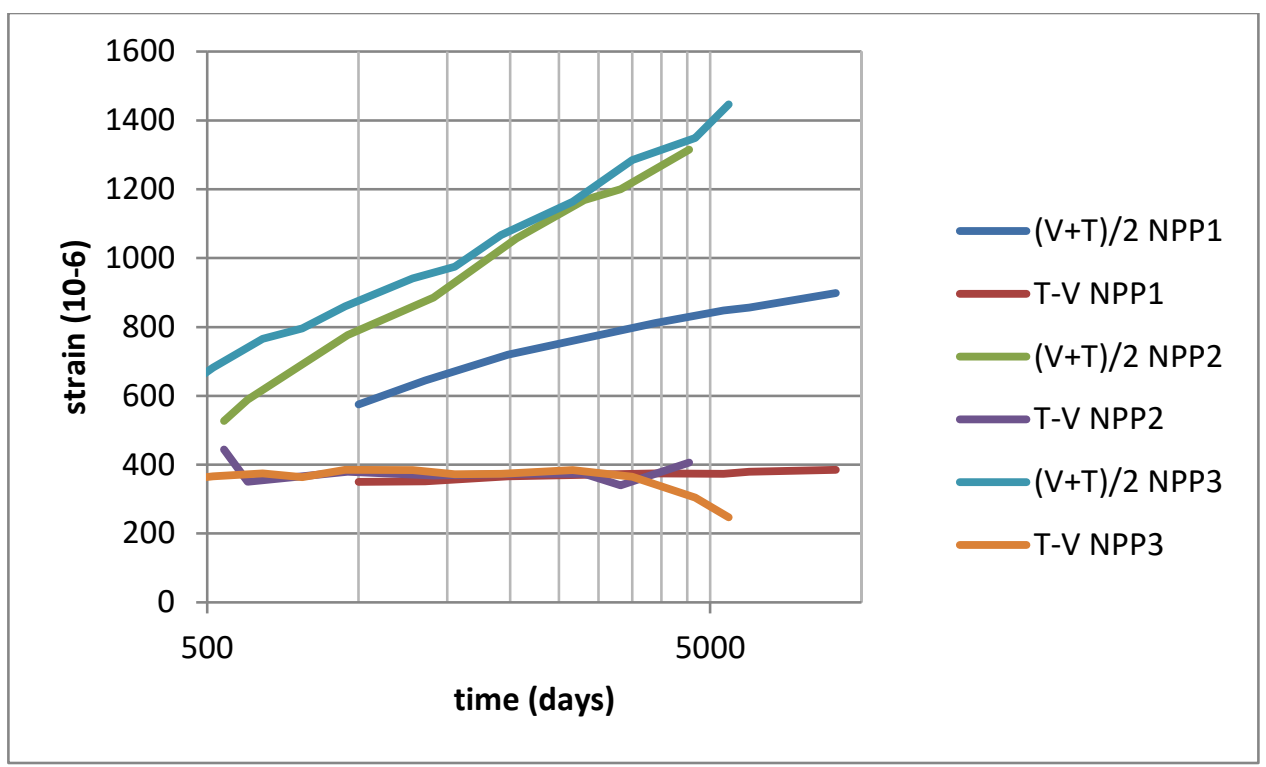

Figure 6. Evolutions of the tangential (T) and vertical (V) deformations in the central part of the containment of the three NPPs - same data as in figure 3.

\section{Modelling}

To model the biaxial behavior of the containment the following assumptions are made:

- Free boundary conditions are assumed (no structural effect),

- Boltzmann superposition principle is used,

- MC2010 relations are used for drying shrinkage, basic and drying creep of concrete and for steel relaxation,

- Kinetics and amplitude of drying shrinkage, basic and drying shrinkage could be adjusted by means of 6 parameters (see eq.2) to experimental results (laboratory tests or in-situ measurements),

- Uniaxial relations for creep are extended to 3D by means of two constant Poisson ratio for basic and desiccation creep - see (Aili et al., 2015) for a discussion about Poisson ratio for creep,

- The vertical prestressing corresponds to a vertical stress of $8,5 \mathrm{MPa}$ and a tangential stress of 12MPa.

To limit the number of parameters when adjustments are made Poisson ratio is taken equal to 0,35 for basic creep (Galenne et al., 2013) and -1 for drying creep (as recommended in the French national annex of Eurocode 2 part 1). Then, three scenarii are tested:

- 1st scenario: MC2010 relations are directly used

- 2nd scenario: MC2010 relations are adjusted to laboratory data (like in figure 4)

- 3rd scenario: MC2010 relations are adjusted to in-situ measurements

Figure 7 shows the comparison between experimental results and the modellings following the three different scenarii. One can see that: 
- MC2010 relations underestimate the delayed deformations (scenario 1),

- with adjustment of the MC2010 relations for creep on laboratory tests, delayed strains are closer of the measured ones but still underestimated (scenario 2),

- it is possible to adjust MC2010 relations to obtain a good agreement with insitu measurements (scenario 4). Figure 8 shows the results of the modelling following this scenario and measurements corresponding to figure 6 (difference between tangential and vertical strains). These results indicate that it is possible to predict the behavior of the containment on a reasonable period of time.

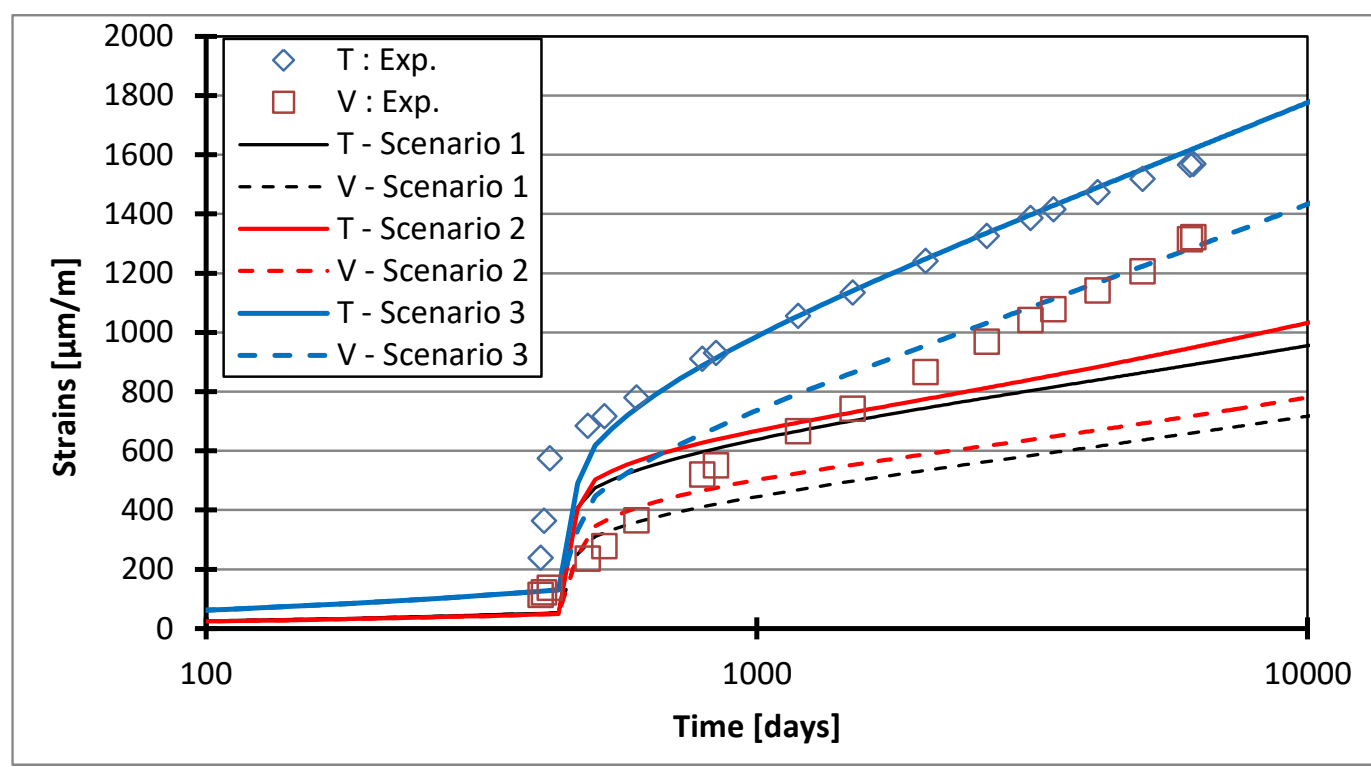

Figure 7. Comparison between in-situ measurements of tangential and vertical strains and modelling following the three scenarii

It should be emphasized that due to the large number of unknown factors when using only measurements on structures (at least 10 parameters: Young modulus; elastic, basic creep and drying creep Poisson ratio; amplitude and kinetic correction factor related to drying shrinkage, basic and drying creep), it is possible to find by inverse analysis a large number of material parameters allowing for reproducing rather correctly the experimental measurements. The analysis of the possible sets of parameters is actually conducted. Besides, the vertical and tangential prestress is supposed to be applied instantaneously. In reality, the duration of the prestress application last approximatively 3 and 7 months for the tangential and vertical prestress, respectively. It explains partially that it is difficult with here to capture the beginning of the vertical strain evolution. 


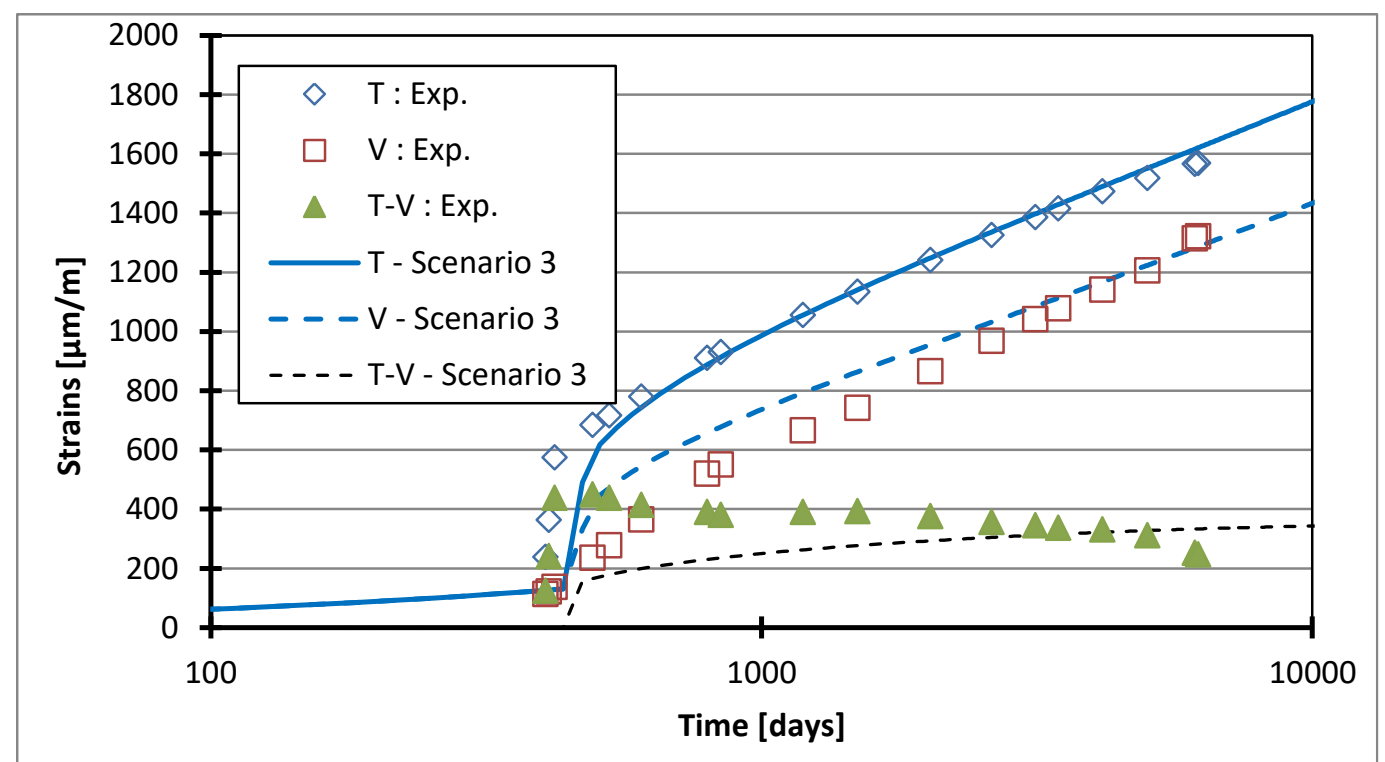

Figure 8. Comparison between in-situ measurements of tangential and vertical strains and of the difference between theses strains and modelling following the scenario 3.

Table 1. set of parameters for the three scenarii of figure 7.

\begin{tabular}{ccccc}
\hline & & Scenario 1 & Scenario 2 & Scenario 3 \\
\hline Drying & Amplitude & 1 & 0.95 & 2.4 \\
\cline { 2 - 5 } shrinkage & kinetics & 1 & 1.05 & 0.95 \\
\hline \multirow{2}{*}{$\begin{array}{c}\text { Basic } \\
\text { creep }\end{array}$} & Amplitude & 1 & 2.71 & 3.2 \\
\cline { 2 - 5 } & kinetics & 1 & 0.063 & 0.73 \\
\hline \multirow{2}{*}{$\begin{array}{c}\text { Drying } \\
\text { creep }\end{array}$} & Amplitude & 1 & 1.28 & 2.3 \\
\cline { 2 - 5 } & kinetics & 1 & 0.43 & 1.93
\end{tabular}

\section{CONCLUSION}

The main conclusions of this work are the following ones:

- Very long term creep in laboratory or of real structures seems to be nonasymptotic

- Using a long test (3 years) in a laboratory is not enough to assess the long term behavior of a massive structure for several decades. We need physical relations for creep in codes in order to predict correctly the delayed behavior of massive structures!

- Biaxial creep of nuclear power plant could be modelled using data of the structure itself. This would allow to predict the delayed behavior of these structures. Further work is needed to improve the prediction in the design phase.

In short-term perspective, effect of temperature will be investigated (the service temperature in a NPP is around $40^{\circ} \mathrm{C}$ ), since it will increase delayed strains and prestress relaxation. In mid-term perspective, numerical simulations will be 
undertaken (Benboudjema and Torrenti, 2014; Hilaire et al., 2014), and compared in order to investigate the structural effects such as gradients of shrinkage and restraint (dome and raft foundation).

\section{REFERENCES}

Aili A., Vandamme M., Torrenti J.-M., Difference Between Creep And Relaxation Poisson's Ratios: Theoretical And Practical Significance For Concrete Creep Testing, Concreep10 conference, 2015.

Barré F., Chauvel D., Coste J.-F., Ragouin R., Rospars C., Torrenti J-M., Enhancement of the assessment of the concrete creep and shrinkage strains, colloque TINCE 2014, Paris, 2014.

Bažant, Z. P., Hubler, M., Yu, Q., Excessive creep deflections: An awakening. Concrete international, $\mathrm{n}^{\circ} 33(8), \mathrm{pp}$ 44-46, 2011.

Benboudjema F., Torrenti J.-M., Modelling desiccation shrinkage of large structures, European Physics Journal Conferences. Volume 56, 2013

Brooks J. J., 30-Year creep and shrinkage of concrete. Mag. Concr. Res., 57(9), 545$556,2005$.

EN1992-1-1, Eurocode 2, Calcul des structures en béton, Partie 1-1 : Règles générales et règles pour les bâtiments, octobre 2005.

Galenne E., Foucault A., Hamon F., Prediction of Delayed Strain of Nuclear Containment Building: from laboratory tests to an industrial mock-up, TINCE 2013, Paris.

Granger L., Comportement différé du béton dans les enceintes de centrales nucléaires : analyse et modélisation, thèse de l'Ecole nationale des ponts et chaussées, 1995.

Hilaire A., Benboudjema F., Darquennes A., Berthaud Y., Nahas G., Modeling basic creep in concrete at early-age under compressive and tensile loading. Nuclear Engineering Design, Volume 269, 2014, pages 222-230, 2014

Muller H., Anders I., Breiner R., Vogel M., Concrete: treatment of types and properties in MC 2010, Structural concrete, Volume 14, Issue 4, pages 320 334, 2013

NF EN 1992-2, Eurocode 2 - Calcul des structures en béton - Partie 2: Ponts en béton - Calcul et dispositions constructives, octobre 2005.

Russel, H.G., Larson, S.C. Thirteen Years of Deformations in Water Tower Place. ACI Structural Journal Vol. 86, No. 2, (1989) 131-145.

Sellier A., Buffo-Lacarrière L., Vers une modélisation simple et unifiée du fluage propre, du retrait et du fluage en dessiccation du béton, $R E G C, \mathrm{Vol} 13, \mathrm{n}^{\circ} 10$, 2009

J.P. Sellin, J.B. Barthelemy, G. Bondonnet, B. Cauvin, J.M. Torrenti, Delayed deformations of concrete structures: the Savines bridge and the Cheviré bridge, MSLB15 conference, Porto, 2015

Troxell, G.E., Raphael, J.E., Davis, R.W., "Long-time creep and shrinkage tests of plain and reinforced concrete," Proc. ASTM 58 (1958), 1101-1120.

Vítek, J., Křístek, V. (2000) Deflections and Strains of Prestressed Concrete Bridges, 16th congress of IABSE, Lucerne, 2000. 